\title{
The Treatment of Women With Epilepsy
}

\author{
Sabine Weil, Charlotte Deppe, Soheyl Noachtar
}

\section{SUMMARY}

Background: Women with epilepsy and their doctors are often unsure of the implications of the disease and the limitations it causes. There is a major need for counseling.

Methods: Selective review of the literature as of November 2009.

Results: Recommendations on pregnancy and childbearing for women with epilepsy can be found in the guidelines issued by the German Societies of Neurology and Epileptology and by the American Epilepsy Society. Only low-level evidence is available on other relevant questions, including contraception, the influence of hormones on epilepsy, and the influence of antiepileptic drugs on endocrine and bone metabolism, because of a lack of controlled studies. Polycystic ovarian syndrome is more commonly seen in women with epilepsy who take valproate. Antiepileptic drugs that induce CYP3a can diminish the efficacy of oral contraceptives; conversely, oral contraceptives can markedly lower the blood levels of antiepileptic drugs. According to the most recent studies, the risk of congenital malformations and spontaneous abortions is $1 \%$ to $2 \%$ in the normal population and $3 \%$ to $9 \%$ in the offspring of women with epilepsy who are taking antiepileptic drugs. Women with epilepsy who want to have children are currently advised to take folic acid prophylactically starting before conception and until the end of the first trimester. New mothers with epilepsy are advised to breastfeed their children.

Conclusion: Proper treatment and counseling of women with epilepsy, with due attention to aspects that are specific to women patients, can reduce the limitations to which they are subject in everyday life.

Cite this as

Weil S, Deppe C, Noachtar S: The treatment of women with epilepsy. Dtsch Arztebl Int 2010; 107(45): 787-93. DOI: 10.3238/arztebl.2010.0787
Klinikum der Universität München, Großhadern; Epilepsie-Zentrum, Neurologische Klinik und Poliklinik: Dr. med. Weil, Prof. Dr. med. Noachta

Klinik und Poliklinik für Frauenheilkunde und Geburtshilfe: Dr. med. Deppe

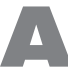
round 400000 women in Germany suffer from epilepsy. Three or four of every 1000 children are born to mothers with epilepsy (1). Surveys reveal that many of the women concerned feel they do not receive proper advice and are indeed objectively poorly informed (2).

The following review discusses the data on epilepsy, hormonal influences (catamenial epilepsy), choice of antiepileptic drugs, influence of drugs on the endocrine metabolism (e.g. polycystic ovary), contraception, conception, and pregnancy that were obtained from a selective review of the literature. The recommendations on conception and pregnancy adhere to the guidelines or recommendations of the German Society of Neurology (Deutsche Gesellschaft für Neurologie) (S1), the German Society of Epileptology (Deutsche Gesellschaft für Epileptologie), and the American Epilepsy Society. Owing to a lack of controlled studies, only low-level evidence is available regarding the other issues.

\section{Seizure frequency and sex hormones}

When a girl reaches puberty there is a sharp rise in the amplitude and frequency of her gonadotropin-releasing hormone $(\mathrm{GnRH})$ pulse, with a consecutive increase in the secretion of follicle-stimulating hormone (FSH) and luteinizing hormone (LH) and rising serum concentrations of estrogens. The progesterone level increases with the increasing number of ovulatory cycles.

Estrogens are ascribed a seizure-promoting effect, although studies on the mechanisms have yielded conflicting findings.

Progesterone has a better-substantiated seizureinhibiting effect $(\mathrm{e} 1,3)$. Some female epilepsy patients describe a cycle-dependent increase in seizures. Figures on the frequency of cycle-related epileptic seizures (catamenial clusters) vary between $10 \%$ and $78 \%$ according to the definition used. A now generally accepted empirical definition of this concentration of seizures requires demonstration of a doubled daily seizure frequency at a particular phase of the ovulatory cycle in at least six consecutive months. According to this definition around a third of women with epilepsy suffer from a cycle-linked increase in the frequency of seizures (3). Three phases with typical catamenial clustering of seizures can be distinguished:

- Periovulatory estrogen peak (days 10 to 13 )

- Perimenstrually with typical fall in gestagen at the end of the cycle (day 3)

- The whole second half of the cycle in disorders of luteal function, i.e., inadequate progesterone level (day 10 to day 3 of next cycle) $(3,4)$ 
TABLE 1

Antiepileptic drugs and their impact on the protection offered by ovulation inhibitors and other hormone-containing contraceptives

\begin{tabular}{|c|c|c|}
\hline $\begin{array}{l}\text { Proven reduction of } \\
\text { contraceptive } \\
\text { protection }\end{array}$ & Possible reduction & $\begin{array}{l}\text { No impact according to } \\
\text { studies or product label }\end{array}$ \\
\hline $\begin{array}{l}\text { - Phenytoin } \\
\text { - Phenobarbital } \\
\text { - Carbamazepine } \\
\text { - Primidone } \\
\text { - Oxcarbazepine }\end{array}$ & $\begin{array}{l}\text { - Topiramate ( } 400 \mathrm{mg} / \mathrm{day} \\
\text { in combination with val- } \\
\text { proate) } \\
\text { - Lamotrigine }\end{array}$ & $\begin{array}{l}\text { - Gabapentin } \\
\text { - Pregabalin } \\
\text { - Valproate } \\
\text { - Ethosuximide } \\
\text { - Lacosamide } \\
\text { - Levetiracetam (<1000 mg/day) } \\
\text { - Zonisamide } \\
\text { - Topiramate < } 200 \mathrm{mg}\end{array}$ \\
\hline
\end{tabular}

A seizure calendar with simultaneous documentation of the menstruation cycle and daily basal temperature helps to resolve any suspicion of catamenial seizure clustering. It may also be useful to determine the progesterone level in the middle of the luteal phase in order to identify cycles with an inadequate luteal phase. Remarkably often, patients' subjective perceptions of perimenstrual clustering of seizures cannot be confirmed objectively.

Treatment options in confirmed cycle-related seizure clustering The only studies published on this topic are open-label investigations with small numbers of patients or case studies, according to which progesterone and progestin, $\mathrm{GnRH}$ analogs, and antiestrogens (clomiphen) have led to a reduction in seizure frequency. Between $42 \%$ and $80 \%$ of women benefited in that they suffered fewer seizures; in a few cases, the seizures ceased completely $(3,5)$. Cyclic administration of clobazam during the perimenstrual phase (10 days) resulted in freedom from seizures in ten of 24 women. In a follow-up study, seizure frequency was reduced by half for 3 years in four of ten women without development of tolerance (e2).

\section{Impact of antiepileptic drugs on the endocrine metabolism}

Significant decreases in LH and estradiol and significant increases in sex-hormone-binding globulins (SHBG) and prolactin can be observed during treatment with antiepileptic drugs (AED) such as phenytoin, phenobarbital, and carbamazepine (6). The increased protein binding that results from the rise in SHBG lowers the serum concentrations of the free active sex steroids.

Polycystic ovary syndrome (PCOS), manifesting with oligo- or amenorrhea, hyperandrogenemia or signs of hyperandrogenization, and polycystic ovaries on sonography, seems to occur more frequently in women with epilepsy, even those who are not taking AED, than in the normal population $(12.5 \%$ to $26 \%$ versus $6.6 \%$ ) $(7,8)$.
Valproate treatment has been linked with the development of PCOS. The endocrine system appears to be affected more often in women who had started on valproate before the age of 20 years (9). Valproate leads to elevation of the testosterone level in up to $57 \%$ of postpubertal girls (e3).

Weight gain, a frequent adverse effect of treatment with valproate, presumably arises from valproateinduced hyperinsulinemia or insulin resistance and from hyperleptinemia with leptin resistance (10). The typical increase in weight can worsen the cardiovascular risk profile (11). Therefore women with epilepsy should be questioned about irregularities of the menstrual cycle, signs of virilization should be checked, and their weight should be documented, so that further investigations can be initiated if required.

\section{Fertility}

Disorders of fertility are more frequent in women with epilepsy than in the normal population (e4). Amenorrhea can be seen in $15 \%$ to $20 \%$ of female epilepsy patients, other disorders of the menstrual cycle, including intracyclic bleeding, in almost 50\% (e5). The precise pathomechanisms have not yet been fully clarified. The possible causes include disturbances of the hypothalamus-hypophysis axis by the epilepsy (e6) and the above-mentioned influence of AED on the endocrine metabolism (e7). Anovulatory cycles, hypogonadotropic amenorrhea, and PCOS are found more often in temporal lobe epilepsy (e8).

\section{Contraception in women with epilepsy}

The efficacy of some AED is affected by oral contraceptives (OC), and vice versa. The AED that can reduce the safety of synthetic contraceptive steroids by increasing their clearance include the strong CYP3a inducers carbamazepine, phenytoin, and phenobarbital and the less powerful CYP3a inducers oxcarbazepine and topimarate (12). Lamotrigine has no effect on the ethinylestradiol level, but lowers the levonorgestrel level by up to $20 \%$ (13). The consequences for contraceptive protection are not known. Table 1 lists the effects of the most commonly used AED on contraceptive protection.

It is assumed that the Pearl index of the most popular contraceptive pills ( 0.1 to 0.7$)$ (e9) doubles on intake of enzyme-inducing AED, although the only evidence for this comes from non-prospective studies with small numbers of cases (13). Contraceptive protection can be improved by long-cycle therapy using a monophasic OC with high progesterone content - at least double the ovulation-inhibiting dose (12). The ovulationinhibiting daily doses of the progestins most often found in contraceptive pills are listed in Table 2. Exclusively gestagen-containing preparations are not safe if enzyme-inducing AED are also being taken and are thus unsuitable.

The above-mentioned interactions between enzymeinducing AED and hormonal contraception also apply to other applications of ovulation-inhibiting substances 
(vaginal rings, plasters) and to other, purely gestagencontaining contraceptives (depot gestagens and subcutaneous gestagen implants).

Women who need enzyme-inducing AED are currently advised not to rely on hormonal preparations, but to choose another form of contraception (e.g., a spiral) and also use condoms.

There are no data regarding the efficacy of the "morning-after pill;" it is not known what doses of progestin are necessary to prevent pregnancy in a woman who is taking enzyme-inducing AED. Current recommendations favor taking $1.5 \mathrm{mg}$ levonorgestrel as soon as possible, followed by $0.75 \mathrm{mg}$ levonorgestrel $12 \mathrm{~h}$ later (12).

One alternative to hormonal contraception is represented by copper-containing spirals (intrauterine device, IUD). The dreaded complication of ascending vaginal infection, possibly culminating in tubo-ovarian abscess, is rare among women in a stable partnership who have no history of recurring vaginal/cervical inflammation. It is currently unknown to what extent the local gestagen effects of hormone spirals may be reduced by enzyme-inducing AED (12).

The serum concentrations of some AED - above all lamotrigine (by as much as 50\%) - are appreciably lowered by contraceptives containing ethinylestradiol. A woman using one of the classic OC with an "off week" may experience cyclical weakening of the effect of AED treatment or toxic drug concentrations during the 7 days when she is not taking the pill (14). These fluctuations can be avoided by long-cycle therapy with monophasic preparations. In some cases the dosage of lamotrigine may need to be adjusted at the beginning and the end of hormonal contraception.

\section{Pregnancy and epilepsy}

\section{Risk of transmission}

Epilepsy is etiologically heterogeneous and is caused by a large number of genetic and non-genetic factors (15). Only in very rare monogenic forms of epilepsy is the genetic risk chromosomally defined and precisely quantified. The generalized epilepsy syndromes bear a somewhat higher risk of inheritance than the focal forms of epilepsy. Taking all syndromes together, the risk of transmission is $4 \%$ to $5 \%$ for children of women with epilepsy and ca. $2 \%$ for those whose fathers have epilepsy (15). More than $90 \%$ of all patients with epilepsy have no family history of the disease.

\section{Epileptic seizures during pregnancy}

In $67 \%$ of women with epilepsy the frequency of seizures stays unaltered during pregnancy, in $17 \%$ there is an increase, and in 16\% seizure frequency decreases (16).

For fear of harming the unborn child, AED are often reduced or discontinued; this can cause an increase in seizure frequency. Pharmacokinetic changes during pregnancy, such as alterations in gastric motility, plasma volume, volume of distribution, hepatic and renal function, and protein binding, play a role. This leads to

\section{TABLE 2}

Ovulation-inhibiting daily doses of some commercially available gestagens not combined with estrogen (e18)

\begin{tabular}{l|l}
\hline Gestagen & $\begin{array}{l}\text { Ovulation-inhibiting daily } \\
\text { dose }(\mathrm{mg})\end{array}$ \\
\hline Chlormadinone acetate & $1.5-2$ \\
\hline Cyproterone acetate & 1 \\
\hline Desogestrel & 0.06 \\
\hline Dienogest & 1 \\
\hline Drospirenone & 2 \\
\hline Gestodene & $0.03-0.05$ \\
\hline Levonorgestrel & $0.05-0.06$ \\
\hline Norethisterone & $0.4-0.5$ \\
\hline Lynestrenol & 2.0 \\
\hline Norethisterone acetate & 0.5 \\
\hline
\end{tabular}

\section{TABLE 3}

\section{Malformation rates in the UK Pregnancy Registry} ( $n=3607$ )

\begin{tabular}{l|l|l|} 
& Exposed children & Malformation rate \\
\hline Valproate & 715 & $6.2 \%$ \\
\hline Carbamazepine & 900 & $2.2 \%$ \\
\hline Lamotrigine & 647 & $3.2 \%$ \\
\hline Phenytoin & 82 & $3.7 \%$ \\
\hline
\end{tabular}

For other drugs the case numbers are too small to permit statistically valid conclusions (18) 
BOX 1

\section{European Registry of Antiepileptic Drugs and Pregnancy (EURAP)}

- Please enter pregnant women with epilepsy in the EURAP registry

- German-language information material for women with epilepsy and their doctors can be found at www.eurap.de.

\section{BOX 2a}

\section{Recommendations for women with epilepsy before a planned pregnancy}

- Take 1 to $5 \mathrm{mg}$ folic acid daily

- Avoid combined antiepileptic therapy (if possible)

- Every AED should be taken at the lowest effective dosage

- Avoid beginning valproate if at all possible; consider other drugs

- If valproate is necessary, use the lowest possible amount in delayed-release form, divided into three doses

- Lamotrigine: because of the anticipated decrease in serum concentration, women taking this drug should have their serum level tested (pre-dose sampling, all tests in same laboratory) at the beginning of pregnancy and in the second and third trimesters; the dosage can be adjusted as required.

\section{BOX 2b}

\section{Recommendations for women with epilepsy during pregnancy}

- Avoid major changes in medication

- Take1 to $5 \mathrm{mg}$ folic acid daily during first trimester

- Try to reduce drug treatment to monotherapy at the lowest effective dosage

- Peripartal vitamin $\mathrm{K}$ intake by the mother is currently not recommended fluctuations in drug clearance. For oxcarbazepine and lamotrigine, there is solid evidence of decreased serum levels with an increase in seizures during pregnancy, followed by a rise in serum concentrations after childbirth (17).

Dose adjustments in pregnancy make sense and require comparative data from pre-pregnancy analyses in the same laboratory. If seizures recur, the drug dose has to be increased. After childbirth the renewed rise in serum concentration can lead to adverse effects.

The impact of epileptic seizures on embryogenesis or fetal development is not well documented. It is plausible that the fetus may be at risk in the event of persisting hypoxemia or hypercapnia during generalized tonic-clonic seizures.

One study documented a clear decrease in fetal heart rate to under 120 beats/min (minimum: 60 beats/min) for over 20 min during a short generalized tonic-clonic seizure (e10). Moreover, fetal hemorrhages, early abortions, and stillbirths have been reported after such seizures (e11). Among the 36 cases of status epilepticus registered in the European Pregnancy Registry, one woman had an early abortion and one a stillbirth (16). The fetus may be endangered if a seizure causes the mother to fall, with the risk of uterine injury or placental bruising or detachment.

The central goal of antiepileptic treatment in a pregnant woman remains the complete avoidance of seizures.

\section{Teratogenicity of antiepileptic drugs}

On the basis of the-predominantly retrospective - studies published to date, the risk of congenital malformations and of abortion or miscarriage is higher in women with epilepsy who take AED than in the normal population (3\% to $9 \%$ versus $1 \%$ to $2 \%$ ) $(18$, e 12$)$. Monotherapy involves a much lower risk of malformations than combined therapy (4\% to $6 \%$ versus $6 \%$ to $17 \%)(18$, e12). The highest rate of malformations is seen in children born to women who have been taking valproate at daily doses of more than $1000 \mathrm{mg}$ (Table 3).

There is evidence of substance-specific malformations for valproate (neural tube defects, cleft lip/ jaw/palate), carbamazepine and phenytoin (cleft palate), and phenobarbital (cardiac malformations) (19). Early data from the first large prospective European pregnancy registry (EURAP) are expected soon (Box 1). The current guidelines of the American Epilepsy Society (19) and the German Society for Epileptology (20), recommend that valproate should be avoided during the first trimester of pregnancy. Because of the high efficacy of valproate, particularly in idiopathic generalized epilepsy, these recommendations cannot always be implemented (21, e13) (see Box $2 a$ for further recommendations).

If the patient is already pregnant, switching to other drugs is pointless because it typically takes weeks or months to complete the changeover (for recommendations see Box $2 b$ ). 
Gynecological care of women with epilepsy during pregnancy differs hardly at all from that of healthy women (Box 3).

\section{Delayed development and cognitive deficits}

Pregnancy registries principally record major malformations and abortions. However, an increasing number of studies are showing a dose-dependent association between valproate exposure and low IQ in the children of mothers with epilepsy (22).

\section{Folic acid substitution / prenatal vitamin $\mathrm{K}$ administration}

Folic acid deficiency leads to a higher rate of neural tube defects in the normal population. Neural tube defects are known to occur with valproate (1\% to $2 \%)$ and carbamazepine $(0.5 \%)$. Folic acid substitution is advised for women who take AED and want to conceive. The daily dose varies between $0.4 \mathrm{mg}$ and $5 \mathrm{mg}$ in the first trimester of pregnancy (e14).

All women who want to bear a child are recommended to take $0.4 \mathrm{mg}$ of folic acid each day before conception and during the first trimester. Those taking AED, particularly valproate or carbamazepine, are advised to take $5 \mathrm{mg}$ folic acid daily. Because the neural tube closes very early (on the $26^{\text {th }}$ day after conception), all women of child-bearing age who have epilepsy and are not using safe means of contraception should take folic acid.

It was long suspected that children born to mothers who had taken enzyme-inducing AED tended to suffer more frequently from early neonatal bleeding. According to recent, albeit sparse, data, however, this risk is not significantly elevated. For this reason, the women concerned are currently not recommended to take vitamin $\mathrm{K}$ prepartum. According to guidelines in the USA, children born to drug-treated women with epilepsy should receive vitamin K postnatally in the same dosage as all other neonates (23).

\section{Complications of pregnancy}

Current data suggest that the risk of premature birth, cesarean section, bleeding during pregnancy, or premature contractions is not significantly increased in women with epilepsy who take AED (19). Only for those who smoke has a higher risk for premature contractions been described. Exposure to AED is thought to double the risk of delayed intrauterine development (small for gestational age, SGA). The 2-min APGAR score is more frequently under 7 in neonates exposed to AED (19).

\section{Childbirth}

Delivery should take place at a center staffed by specialists in obstetrics, neurology, neonatology, and anesthesia. Home birth is not advised.

As a rule an epileptic seizure ends naturally after only a few minutes. The simple fact that drugs need time to take effect means there is no point in administering medication. Exceptions are a seizure lasting more than $5 \mathrm{~min}$ and status epilepticus. The first

\section{Recommended in addition to standard antenatal care}

- Extended first-trimester sonography screening between 11 and 14 weeks of gestation

- Detailed organ screening at a specialized center between 20 and 22 weeks of gestation

priority during a seizure is to protect mother and unborn child from injury (falls, abdominal compression). Placing a wedge in the mouth is obsolete.

If it becomes necessary to suppress a seizure, lorazepam should be preferred to diazepam because of its superior antiepileptic action and its lesser adverse effect on respiratory function (e15).

Pediatricians should always be on hand so that if a seizure occurs during childbirth the medical team can react without delay in the event of excessively prolonged sedation or when the child of a mother in status epilepticus develops hypoxia.

According to the EURAP study, the likelihood of an epileptic seizure during childbirth is $3.5 \%$; the risk correlates closely with the number of seizures during pregnancy (16).

Epilepsy does not indicate cesarean section or induction of labor per se. Cesarean section is recommended for women who suffer several minor seizures every day or at least one generalized tonic-clonic seizure per week, however, and may be indicated if birth is excessively prolonged, because particularly in generalized forms of epilepsy sleep deprivation increases the risk of a seizure. Sleep deprivation has a much lower impact on focal epilepsy (e16). Women with epilepsy should continue to take their normal dosage of AED during childbirth.

\section{After childbirth}

Mothers with epilepsy need to be informed about the risks they face. Sleep deprivation from breastfeeding can evoke seizures, so support is required. Diaper changing should be done on the floor, to avoid any risk of the child falling if the mother should have a seizure and lose consciousness. Infants should be bathed only in the presence of another adult (24).

\section{Breastfeeding}

Mothers with epilepsy are not currently advised to desist from breastfeeding (17). All AED cross over into the breast milk in varying proportions (e11, e17). However, the plasma concentration of AED in the child is not determined solely by the amount of drug in the milk. Some AE may accumulate because the neonatal liver is not yet fully developed and drug elimination is delayed. 


\section{Osteoporosis}

More than half of all epilepsy patients on long-term AED treatment suffer from AED-induced osteopathy (25). The risk of fractures is 5 to 6 times higher in epilepsy patients. Enzyme-inducing AED are known to have a negative impact on vitamin D metabolism. Valproate is thought to alter the ratio of osteoblasts and osteoclasts in favor of the latter. Newer AED have not yet been properly studied in this regard. The age of the patient should be a factor in deciding which AED to prescribe. Bone density measurement is therefore recommended before and 5 years after commencement of AED treatment in postmenopausal women.

\section{Conflict of interest statement}

Prof. Noachtar declares honoraria for consultation and lectures, support for research, and/or participation in clinical studies from the following companies: Aventis, Desitin, Eisai, Glaxo-Wellcome, Janssen-Cilag, Johnson \& Johnson, Novartis, Pfizer und UCB Pharma.

Dr. Weil has received honoraria for lectures from UCB.

Dr. Deppe declares that no conflict of interest exists according to the guidelines of the International Committee of Medical Journal Editors.

Manuscript received on 25 November 2009, revised version accepted on 31 May 2010

Translated from the original German by David Roseveare.

\section{REFERENCES}

1. Yerby MS: Quality of life, epilepsy advances, and the evolving role of anticonvulsants in women with epilepsy. Neurology 2000; 55: 21-31; discussion 54-28.

2. May TW, Pfafflin M, Coban I, Schmitz B: Frauen und Epilepsie: Befürchtungen, Wissen, Beratungsbedarf. Nervenarzt 2009; 80 174-83.

3. Herzog AG: Catamenial epilepsy: definition, prevalence, pathophysiology, and treatment. Seizure 2008; 17: 151-9.

4. Herzog AG, Klein P, Ransil BJ: Three patterns of catamenial epilepsy. Epilepsia 1997; 38: 1082-8.

5. Foldvary-Schaefer N, Falcone T: Catamenial epilepsy: pathophysiology, diagnosis, and management. Neurology 2003; 61: 2-15.

6. Bauer J: Interactions between hormones and epilepsy in female patients. Epilepsia 2001; 42(Suppl 3): 20-2.

\section{KEY MESSAGES}

- In light of what we know about its teratogenicity, valproate should not be instituted in women who want children unless there is no alternative.

- Valproate can lead to weight gain from hyperinsulinemia.

- Some antiepileptic drugs (AED) may interfere with the effect of oral contraceptives. Conversely, oral contraceptives may cause significant decreases in the concentrations of AED

- Half of all women with epilepsy on long-term AED treatment suffer from AED-induced osteopathy with an elevated fracture risk.
7. Bilo L, Meo R: Epilepsy and polycystic ovary syndrome: where is the link? Neurol Sci 2006; 27: 221-30.

8. Herzog AG, Schachter SC: Valproate and the polycystic ovarian syndrome: final thoughts. Epilepsia 2001; 42: 311-5.

9. Isojarvi Jl, Laatikainen TJ, Pakarinen AJ, Juntunen KT, Myllyla W: Polycystic ovaries and hyperandrogenism in women taking valproate for epilepsy. N Engl J Med 1993; 329: 1383-8.

10. Rauchenzauner M, Haberlandt E, Scholl-Burgi S, et al.: Effect of valproic acid treatment on body composition, leptin and the soluble leptin receptor in epileptic children. Epilepsy Res 2008; 80: 142-9.

11. Pylvanen V, Pakarinen A, Knip M, Isojarvi J: Insulin-related metabolic changes during treatment with valproate in patients with epilepsy. Epilepsy Behav 2006; 8: 643-8.

12. Schwenkhagen AM, Stodieck SR: Which contraception for women with epilepsy? Seizure 2008; 17: 145-50.

13. O'Brien MD, Guillebaud J: Contraception for women with epilepsy. Epilepsia 2006; 47: 1419-22.

14. Christensen J, Petrenaite V, Atterman J, et al.: Oral contraceptives induce lamotrigine metabolism: evidence from a double-blind, placebo-controlled trial. Epilepsia 2007; 48: 484-9.

15. Winawer MR, Shinnar S: Genetic epidemiology of epilepsy or what do we tell families? Epilepsia 2005; 46(Suppl 10): 24-30.

16. Eurap Study Group: Seizure control and treatment in pregnancy: observations from the EURAP epilepsy pregnancy registry. Neurology 2006; 66: 354-60.

17. Pennell PB: 2005 AES annual course: evidence used to treat women with epilepsy. Epilepsia 2006; 47(Suppl 1): 46-53.

18. Morrow J, Russell A, Guthrie E, et al.: Malformation risks of antiepileptic drugs in pregnancy: a prospective study from the UK Epilepsy and Pregnancy Register. J Neurol Neurosurg Psychiatry 2006; 77 : 193-8.

19. Harden CL, Meador KJ, Pennell PB, et al.: Practice parameter update: management issues for women with epilepsy — focus on pregnancy (an evidence-based review): teratogenesis and perinatal outcomes: report of the Quality Standards Subcommittee and Therapeutics and Technology Assessment Subcommittee of the American Academy of Neurology and American Epilepsy Society. Neurology 2009; 73: $133-41$.

20. Schmitz B, Denning, D, Dietz, R, Steinhoff B, Mayer, T: Valproate for women with epilepsy; a recommendation of the German Chapter of international League against Epilepsy. Eurap homepage: www. eurap.de 2010

21. Marson AG, Al-Kharusi AM, Alwaidh M, et al.: The SANAD study of effectiveness of valproate, lamotrigine, or topiramate for generalised and unclassifiable epilepsy: an unblinded randomised controlled trial. Lancet 2007; 369: 1016-26.

22. Meador KJ, Baker GA, Browning N, et al.: Cognitive function at 3 years of age after fetal exposure to antiepileptic drugs. $N$ Engl J Med 2009; 360: 1597-605.

23. Harden CL, Pennell PB, Koppel BS, et al.: Practice parameter update: management issues for women with epilepsy-focus on pregnancy (an evidence-based review): vitamin K, folic acid, blood levels, and breastfeeding: report of the Quality Standards Subcommittee and Therapeutics and Technology Assessment Subcommittee of the American Academy of Neurology and American Epilepsy Society. Neurology 2009; 73: 142-9.

24. Bagshaw J, Crawford P, Chappell B: Problems that mothers' with epilepsy experience when caring for their children. Seizure 2008; 17: 42-8.

25. Bartl R: Antiepileptika-induzierte Osteopathie. Formen, Pathogenese, Prophylaxe, Früherkennung, Therapie. Dtsch Med Wochenschr 2007: 132: 1475-9. 
Corresponding author

Prof. Dr. med. Soheyl Noachtar

Epilepsie-Zentrum

Neurologische Klinik und Poliklinik

Klinikum der Universität München - Großhadern

Marchioninistr. 15

81377 München, Germany

noa@med.uni-muenchen.de

(2) For eReferences please refer to:

www.aerzteblatt-international.de/ref 4510 


\section{REVIEW ARTICLE}

\section{The Treatment of Women With Epilepsy}

Sabine Weil, Charlotte Deppe, Soheyl Noachtar

\section{eReferences}

e1. Scharfman HE, MacLusky NJ: The influence of gonadal hormones on neuronal excitability, seizures, and epilepsy in the female. Epilepsia 2006; 47(9): 1423-40.

e2. Feely M, Gibson J: Intermittent clobazam for catamenial epilepsy: tolerance avoided. J Neurol Neurosurg Psychiatry 1984; 47(12): 1279-82.

e3. Vainionpaa LK, et al.: Valproate-induced hyperandrogenism during pubertal maturation in girls with epilepsy. Ann Neurol 1999; 45(4): 444-50.

e4. Herzog AG, et al.: Reproductive endocrine disorders in men with partial seizures of temporal lobe origin. Arch Neurol 1986; 43(4): 347-50.

e5. Herzog AG, et al.: Reproductive endocrine disorders in women with partial seizures of temporal lobe origin. Arch Neurol 1986; 43(4): $341-6$.

e6. Herzog AG: Is there a lateralized asymmetry in the sensitivity of the brain to hormones in epilepsy? Epilepsy Behav 2007; 11(2): $157-9$.

e7. Isojarvi J: Disorders of reproduction in patients with epilepsy: antiepileptic drug related mechanisms. Seizure 2008; 17(2): 111-9.

e8. Cummings LN, Giudice L, Morrell MJ: Ovulatory function in epilepsy. Epilepsia 1995; 36(4): 355-9.

e9. Deutsche Gesellschaft für Gynäkologie und Geburtshilfe e.V. Leitlinien zur Empfängnisverhütung. www.uni-duesseldorf.de/AWMF/ I//015-015.htm

e10. Teramo $\mathrm{K}$, et al.: Fetal heart rate during a maternal grand mal epileptic seizure. J Perinat Med 1979: 7(1): 3-6.

e11. Pennell, PB: Antiepileptic drug pharmacokinetics during pregnancy and lactation. Neurology 2003; 61(6)(Suppl 2): 35-42.

e12. Crawford P: Best practice guidelines for the management of women with epilepsy. Epilepsia 2005; 46(Suppl 9): 117-24.

e13. Kommission für Leitlinien der Deutschen Gesellschaft für Neurologie. Leitlinien für Diagnostik und Therapie in der Neurologie. 4. überarbeitete Auflage 2008. Thieme Verlag 2008. (Online: www. dgn.org/-leitlinien-online.html).

e14. Yerby, MS: Management issues for women with epilepsy: neural tube defects and folic acid supplementation. Neurology 2003; 61(6)(Suppl 2): 23-6.

e15. Reiman DM, et al.: A comparison of four treatments for generalized convulsive status epilepticus. Veterans Affairs Status Epilepticus Cooperative Study Group. N Engl J Med 1998; 339(12): 792-8.

e16. Malow BA, et al.: Sleep deprivation does not affect seizure frequency during inpatient video-EEG monitoring. Neurology 2002; 59(9): 1371-4.

e17. Tomson T, et al.: Pharmacokinetics of levetiracetam during pregnancy, delivery, in the neonatal period, and lactation. Epilepsia 2007; 48(6): 1111-6.

e18. Leidenberger F e. Klinische Endokrinologie für Frauenärzte. Heidelberg: Springer Verlag 2005 